\title{
Enhanced Electrochemiluminescence from a Stoichiometric Ruthenium(II)-Iridium(III) Complex Soft Salt
}

\author{
Kalen N. Swanick, ${ }^{[a]}$ Martina Sandroni, ${ }^{[b]}$ Zhifeng Ding, ${ }^{*}{ }^{[a]}$ and Eli Zysman-Colman ${ }^{*[b, c]}$
}

\begin{abstract}
Electrochemiluminescence $(E C L)$ and electrochemistry are reported for a heterometallic soft salt, $\left[\mathrm{Ru}(\mathrm{dtbubpy})_{3}\right]\left[\operatorname{Ir}(\mathrm{ppy})_{2}(\mathrm{CN})_{2}\right]_{2}$ ([Ir] $\left.[\mathrm{Ru}][\mathrm{Ir}]\right)$, consisting of a $2: 1$ ratio of complementary charged $\mathrm{Ru}$ and $\mathrm{Ir}$ complexes possessing two different emission colors. The $[R \mathbf{R u}]^{2+}$ and $[\mathbf{I r}]$ moieties in the [Ir][Ru][Ir] greatly reduce the energy required to produce ECL. While ECL intensity in the annihilation path was enhanced $18 x$ relative to that of $\left[\mathrm{Ru}(\mathrm{bpy})_{3}\right]^{2+}, \mathrm{ECL}$ in the co-reactant path with tri-npropylamine was enhanced a further $4 x$. Spooling spectroscopy gives insight into ECL mechanisms: the unique light emission at 634 $\mathrm{nm}$ is due to the $[\mathbf{R u}]^{2+*}$ excited state and no [Ir] ${ }^{*}$ was generated in either route. Overall, the soft salt system is anticipated to be attractive and suitable for the development of efficient and low energy cost ECL detection systems.
\end{abstract}

\section{Introduction}

Electrochemiluminescence or electrogenerated chemiluminescence (ECL) is an emerging and sensitive tool for analyte detection, devices, and biological probes. ${ }^{[1]} \mathrm{ECL}$ is emitted through bimolecular recombination of radicals that are electrochemically generated in solution. Radical species can be generated from a single molecular emitter (annihilation mechanism) or through a bimolecular set of electrochemical and chemical reactions between the emitter and a suitable coreactant (co-reactant mechanism). The seminal ECL system in fact is based on $\left[\mathrm{Ru}(\mathrm{bpy})_{3}\right]^{2+} /$ tri- $n$-propylamine (TPrA) coreactant scheme (bpy $=2,2^{\prime}$-bipyridine) ${ }^{[2]}$ Most ECL studies involve single luminophores and thus a unique emission process. The search for high-efficiency ECL reagents that can emit over the entire visible spectrum is intense and much recent interest has focussed on neutral ${ }^{[3]}$ and charged $\left.^{[1 \mathrm{k},} 4\right]$ iridium(III) mononuclear complexes to address these design challenges.

Based on the pioneering work by Richter and co-workers, ${ }^{[5]}$ Hogan and Francis et al. showed how mixtures of luminophores in the presence of TPrA could be addressed at different potentials and thus produce ECL systems with multiple emissive readouts. $^{[11,6]}$ Independently, pursuing a "lab-on-a-molecule"[7] design, Schmittel et al. have investigated the ECL behavior of oligonuclear $\operatorname{Ir}(\mathrm{III})-\mathrm{Ru}(\mathrm{II})$ and $\operatorname{Ir}(\mathrm{III})-\mathrm{Ru}(\mathrm{II})-\mathrm{Ir}(\mathrm{III})$ systems with

[a] Dr. K.N. Swanick and Prof. Dr. Z. Ding

Department of Chemistry

The University of Western Ontario

1151 Richmond Street, London, Ontario, N6A 5B7, Canada

E-mail: zfding@uwo.ca

[b] Dr. M. Sandroni and Prof. Dr. E. Zysman-Colman

Département de Chimie

Université de Sherbrooke

2500 Blvd de l'Université, Sherbrooke, J1K 2R1, Canada

[c] Dr. E. Zysman-Colman

Organic Semiconductor Centre, EaStCHEM School of Chemistry

University of St Andrews

St Andrews, Fife, KY16 9ST, UK

E-mail: eli.zysman-colman@st-andrews.ac.uk

URL: www.zysman-colman.com

Supporting information for this article including supplementary ECL data is given via a link at the end of the document.
TPrA wherein the metals are electronically isolated but covalently attached. ${ }^{[8]}$ They demonstrated that in these systems different ECL and photoluminescence (PL) behavior exists and that multiple ECL emissions are possible through recombination of different radical cationic species with the co-reactant. We illustrated that multiple ECL signals could be obtained under self-co-reactant conditions from the same luminophore by generating species at different oxidation states. ${ }^{[9]}$ Recently, Hogan et al. elegantly demonstrated electrochemicallycontrolled reversible emission switching from two separate luminophores within the same solution for independent emission detection. ${ }^{[1 \mathrm{i}, 6 \mathrm{~b}]}$

Herein we report for the first time the electrochemistry and $\mathrm{ECL}$ of the heterometallic soft salt [Ru(dtbubpy $\left.)_{3}\right]\left[\operatorname{Ir}(\mathrm{ppy})_{2}(\mathrm{CN})_{2}\right]_{2}$ (dtbubpy = 4,4'-di-t-butyl-2,2'-bipyridine; $\quad$ ppyH $=2$ phenylpyridine), [Ir][Ru][Ir], that is a $2: 1$ stoichiometric mixture of complexes containing a cationic $\left[\mathrm{Ru}(\mathrm{dtbubpy})_{3}\right]^{2+[10]}$ and an anionic $\quad\left[\operatorname{lr}(\mathrm{ppy})_{2}(\mathrm{CN})_{2}\right]^{-[11]}$ with significant ion-pairing interaction $^{[12]}$ under both annihilation and co-reactant conditions. The unique soft salt is composed of a red-orange-emitting ruthenium(II) cation and a blue-green-emitting iridium(III) anion. We compare [Ir][Ru][Ir] with reference complexes $\left[\mathrm{Ru}(\mathrm{dtbubpy})_{3}\right] \mathrm{Cl}_{2},[\mathbf{R u}] \mathrm{Cl}_{2}$, and $\mathrm{TBA}\left[\operatorname{Ir}(\mathrm{ppy})_{2}(\mathrm{CN})_{2}\right], \mathbf{T B A}[\mathbf{I r}]$ as well as their 1:2 mixture in solution (TBA $=$ tetra- $n$ butylammonium). ${ }^{[12 b]}$ Surprisingly, the ECL signal of [Ir][Ru][Ir] reflects emission solely from the [Ru] moiety. This observation distinguishes this system from recently reported mixtures of ECLphores by Hogan and Francis wherein they can selectively excite each complex as a function of potential. ${ }^{[1,6 a]}$ Coincident with our present report, Frisbie and co-workers reported how a mixture of $\left[\operatorname{Ir}(\mathrm{dFppy})(\mathrm{bpy}) \mathrm{PF}_{6}\right.$ and $\left[\mathrm{Ru}(\mathrm{bpy})_{3}\right]\left(\mathrm{PF}_{6}\right)_{2}$ in a polymer gel resulted in uniquely Ru-based emission under annihilation conditions. $^{[1 \mathrm{~g}]}$ In the case of [Ir][Ru][Ir] ECL is probably generated from [Ir] $]^{\bullet}$ and [Ru $^{+\bullet}$ annihilation, which therefore reduces the energy required to emit light from $[\mathbf{R u}]^{*}$. A significant enhancement in ECL intensity was observed from the soft salt solution, which is further enhanced by adding TPrA as a co-reactant.

\section{Results and Discussion}

The electrochemical properties ${ }^{[1 \mathrm{k}, 13]}$ of $[\mathbf{R u}] \mathbf{C l}_{2}, \mathrm{TBA}[\mathbf{I r}]$ and the soft salt [Ir][Ru][Ir] were assessed in acetonitrile, using $\mathrm{TBAPF}_{6}$ as the supporting electrolyte. The data are gathered in Table 1, and the cyclic voltammograms (CVs) are shown in Figure 1, together with the corresponding ECL-voltage curves. Similar to $\left[\mathrm{Ru}(\mathrm{bpy})_{2}\right]^{2+},{ }^{[2 c]}$ red-orange-emitting $[\mathbf{R u}] \mathrm{Cl}_{2}$ exhibits a reversible oxidation at $1.11 \mathrm{~V}$ vs. SCE, corresponding to the $\mathrm{Ru}^{\mathrm{II/III}}$ couple, and a reversible reduction at $-1.45 \mathrm{~V}$, attributed to electron injection into the LUMO mostly contributed from the dtbubpy ligands (Figure 1a). The chloride oxidation as that in the case of $\left[\mathrm{Ru}(\mathrm{bpy})_{3}\right] \mathrm{Cl}_{2}{ }^{[2 \mathrm{cc}}$ was not observed in the potential window, indicating that $\left[\mathrm{Ru}^{12+}\right.$ is easier to be oxidized than $\mathrm{Cl}^{\text {' }}$. Blue-green-emitting TBA[Ir] is characterized by an irreversible oxidation at $0.98 \mathrm{~V}$ and a reversible reduction at $-2.32 \mathrm{~V}$, displaying a much larger electrochemical energy gap $\left(\Delta \mathrm{E}_{\text {redox }}\right)$ 
than that of $[\mathbf{R u}] \mathrm{Cl}_{2}$ (Figure $1 \mathrm{~b}$ ). The oxidation process is centered on iridium centre with significant contributions from the phenyl rings of the ppy ligands, while the reduction is mainly localized on the pyridyl rings. The electrochemical data for these reference compounds match those reported in the literature. ${ }^{[14]}$

The first reduction and oxidation of [Ir][Ru][Ir] show a superposition of partial features of the two reference complexes
(Figure 1c). The reduction wave corresponds to that of $[R u]^{2+}$ (Figure 1a). The oxidation centered on Ir is the first oxidation wave for the soft salt, an irreversible process identical to that of TBA[Ir] (Figure 1b). The ratio of the reduction current peak height to the oxidation one is $1: 2$ corresponding to the stoichiometry of the soft salt. For ECL, typically the $[\mathrm{Ru}]^{2+}$ and

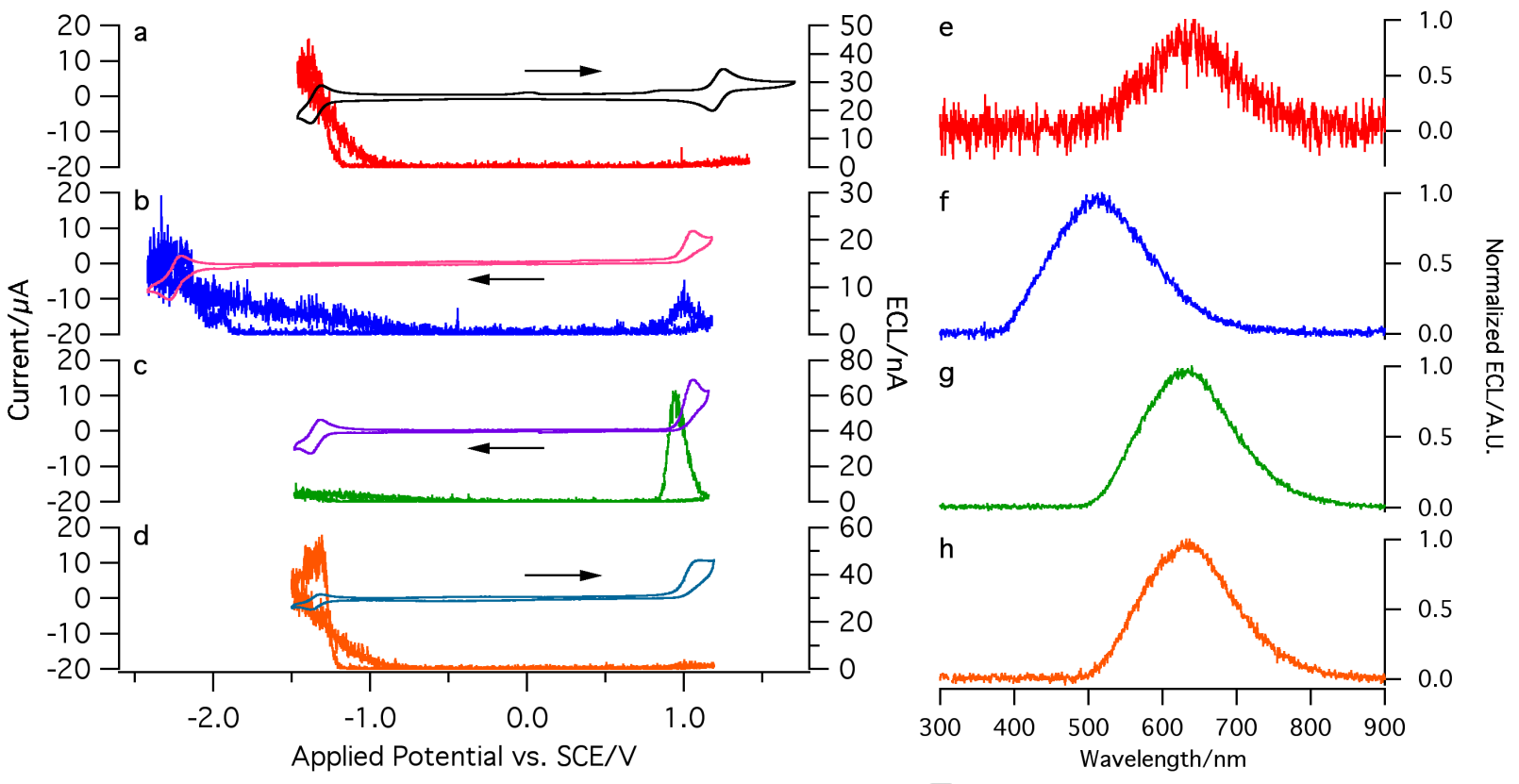

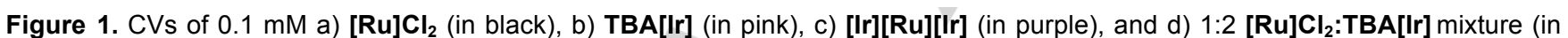
blue) in potential ranges between their $1^{\text {st }}$ reduction and $1^{\text {st }}$ oxidation, along with the corresponding ECL-voltage curves in red (a), blue (b), green (c), and orange (d), respectively. Scan rate was at $0.1 \mathrm{~V} / \mathrm{s}$. First cycle is shown, and arrows indicate the scan direction.

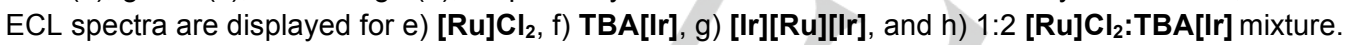

Table 1. Electrochemical and ECL data ${ }^{a}$

\begin{tabular}{llll}
\hline Complex & $\mathrm{E}_{1 / 2} / \mathrm{V}$ & $\Delta \mathrm{E}_{\text {redox }} / \mathrm{eV}$ & $\lambda_{\max }(\mathrm{ECL}) / \mathrm{nm}^{\mathrm{d}}$ \\
\hline [Ru]CI & & 2.56 & 638 \\
TBA[Ir] & $-1.45 ; 1.11$ & 3.30 & 517 \\
[Ir][Ru][Ir] & $-2.32 ; 0.98^{\mathrm{b}}$ & & \\
& $-1.60 ;-2.33 ;-1.86 ;$ & 2.42 & 634 \\
& $1.14^{\mathrm{b}}$ &
\end{tabular}

${ }^{a}$ CVs were recorded in dry, nitrogen-purged ACN using $0.1 \mathrm{M}$ TBAPF $_{6}$ as the supporting electrolyte. Potentials are reported in $\checkmark$ vs. SCE and were calibrated using an $\mathrm{Fc}^{+} / \mathrm{Fc}$ internal standard $(0.38 \mathrm{~V}$ in $\mathrm{ACN}) .{ }^{[15]}$ b Irreversible, $\mathrm{E}_{\mathrm{pa}}$ is reported; ${ }^{\mathrm{c}}$ Partially reversible. ${ }^{\mathrm{d}}$ Annihilation ECL spectral data.

[Ir] complexes produce ECL from their electrogenerated radicals $[\mathbf{R u}]^{+\bullet}$ and $[\mathbf{R u}]^{3+\bullet}$ (Figure $\left.1 \mathrm{a}\right),[\mathbf{I r}]^{2 \cdot \bullet}$ and [Ir] (Figure $1 \mathrm{~b}$ ), respectively.

The stronger ECL signals in the cathodic region in Figure $1 \mathrm{a}$ and $1 \mathrm{~b}$ for the reference complexes point to a greater stability for the [Ir] $]^{\cdot}$ species of TBA[Ir] and $[\mathbf{R u}]^{3+\cdot}$ species of $[\mathbf{R u}] \mathbf{C l}_{2}$, despite the greater reversibility observed for the $[\mathbf{I r}]^{2 \cdot-}$ species of TBA[Ir] and the $[\mathbf{R u}]^{+\bullet}$ species of $[\mathbf{R u}] \mathbf{C l}_{2}$. Very interestingly, due to contributions from the $[\mathbf{R u}]^{2+}$ and $[\mathbf{I r}]$ - ions in the soft salt, $\mathrm{ECL}$ was generated via the annihilation mechanism involving radicals from both complexes instead of from one species alone
(Figure 1c), in a potential window from 1.16 to $-1.48 \mathrm{~V}$. Initially, $[R u]^{2+}$ is reduced to its radical anion, $[R u]^{+*}$, at $-1.36 \vee($ Eq. 1$)$, and [Ir] is oxidized to its radical cation, [Ir]', at $1.07 \mathrm{~V}$ (Eq. 2). The excited species [Ru $]^{2+\star}$ is generated (Eq. 3), via electron transfer from the HOMO of $[\mathbf{R u}]^{+\bullet}$ to the HOMO of [Ir] (Scheme 1). The $[R u]^{2+*}$ then emits light via relaxation to the ground state (Eq. 4). The [Ru $]^{+*}$ was stabilized while the [Ir] was destabilized in the soft salt, the radical cations appear to be less stable than the radical anions. ECL was generated mostly in the anodic region in contrast to that from the reference mononuclear complexes. The ECL intensity, corresponding to the photons generated, of the [Ir][Ru][Ir] complex is $62 \mathrm{nA}$ compared to 45 $n A$ for $[R u] C_{2}$, an increase of approximately 1.4 times. Lodge and Frisbie's groups recently investigated ECL devices of an iridium(III) complex, Ir(diFppy $)_{2}($ bpy $) P_{6}$ [diFppy $=2-\left(2^{\prime}, 4^{\prime}-\right.$ difluorophenyl)pyridine; bpy $=2,2^{\prime}$-bipyridyl], blended with $\mathrm{Ru}(\mathrm{bpy})_{3}{ }^{2+}$ at various molar ratios in an ion gel. ${ }^{[19]}$ They coincidently discovered that the only red-orange-colored light was enhanced by a factor of 2 . In contrast, Kerr et al reported mixed annihilation $\mathrm{ECL}$ of $\mathrm{Ru}(\mathrm{bpy})_{3}{ }^{2+}$ with various cyclometalated iridium(III) chelates, where dual colors were observed. ${ }^{[1 i]}$

$[\mathrm{Ir}][\mathrm{Ru}]^{2+}[\mathrm{Ir}]+\mathrm{e} \rightarrow[\mathrm{Ir}][\mathrm{Ru}]^{+\cdot}[\mathrm{Ir}]$ 
$[\mathrm{Ir}][\mathrm{Ru}]^{2+}[\mathrm{Ir}] \rightarrow[\mathrm{Ir}]^{*}[\mathrm{Ru}]^{2+}[\mathrm{Ir}]^{\cdot}+2 \mathrm{e}$ $2[\mathrm{Ir}][\mathrm{Ru}]^{+*}[\mathrm{Ir}]+[\mathrm{Ir}]^{*}[\mathrm{Ru}]^{2+}[\mathrm{Ir}]^{*} \rightarrow$
$2[\mathrm{Ir}][\mathrm{Ru}]^{2+*}[\mathrm{Ir}]+[\mathrm{Ir}][\mathrm{Ru}]^{2+}[\mathrm{Ir}]$

$[\mathrm{Ir}][\mathrm{Ru}]^{2+*}[\mathrm{Ir}] \rightarrow[\mathrm{Ir}][\mathrm{Ru}]^{2+}[\mathrm{Ir}]+\mathrm{h} \mathrm{v}_{1}$

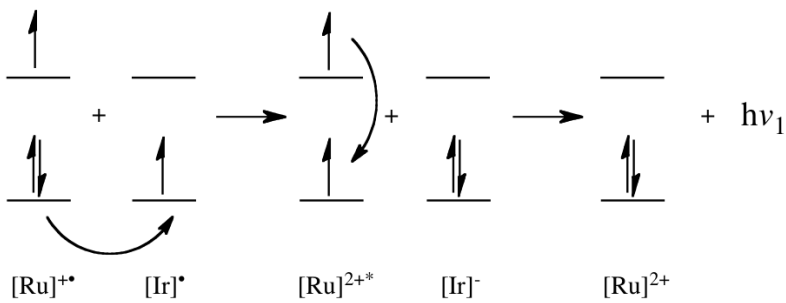

Scheme 1. ECL mechanism for generation of $[\mathbf{R u}]^{2+*}$ excited species.

The ECL efficiencies of [Ru] $\mathbf{C l}_{2}$ and TBA[Ir] were $2.14 \%$, and $2.83 \%$, while [Ir][Ru][Ir] was determined to be $2.51 \%$, (see ECL efficiency calculation, Eq. S1 in SI). Thus, there was no significant ECL efficiency enhancement for the soft salt relative to the reference complexes in this potential region.

The ECL emission spectra were acquired during potential scanning for the three complexes (Figure 1e-1h). ${ }^{[16]}$ The heterometallic [Ir][Ru][Ir] shows an ECL peak wavelength at $634 \mathrm{~nm}$ (Figure 1g), while mononuclear parent complexes display ECL peak wavelengths at $638 \mathrm{~nm}$ for $[\mathbf{R u}] \mathbf{C l}_{2}$ (Figure 1e) and $517 \mathrm{~nm}$ for TBA[Ir] (Figure 1f).

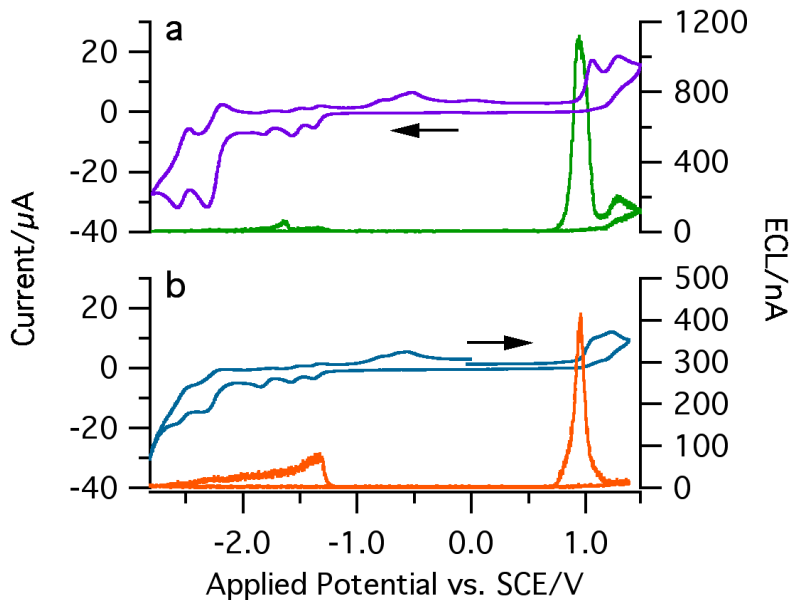

Figure 2. a) CV (in purple) with ECL-voltage curve overlaid (in green) of [Ir][Ru][Ir], in an extended potential range between $1.43 \mathrm{~V}$ and $-2.83 \mathrm{~V}$; b) CV (in blue) with ECL-voltage curve overlaid (in orange) of $1: 2[\mathbf{R u}] \mathrm{Cl}_{2}: \mathrm{TBA}[\mathrm{Ir}]$ mixture solution, in an extended potential range of $1.38 \mathrm{~V}$ to $-2.81 \mathrm{~V}$. Both are shown with an extended potential window. The scan rate was $0.1 \mathrm{~V} / \mathrm{s}$, first cycle shown with arrows showing scan direction.
The ECL spectrum of $[R u] C_{2}$ correlates well with the 298 $\mathrm{K}$ photoluminescence $(\mathrm{PL})$ spectrum in acetonitrile solution $\left(\lambda_{\mathrm{em}}\right.$ $=630 \mathrm{~nm}) \cdot{ }^{[12 \mathrm{~b}]}$ By contrast, the ECL emission of TBA[Ir] is red shifted with respect to the PL spectrum in acetonitrile (structured with main $\lambda_{\text {em }}$ peaks at 477 and $506 \mathrm{~nm}$ ), which is due to the higher concentration was used during the $\mathrm{ECL}$ experiments, internal filter effect (self-absorption) and instrument effects. ${ }^{[17]}$ Finally, the ECL of $[\mathrm{Ir}][\mathrm{Ru}][\mathrm{Ir}]$ is characterized by pure $[\mathrm{Ru}]^{2+}$ emission, indicating that $[R u]^{2+*}$ is the only excited species formed during the electrochemical process. These observations corroborate our proposed ECL mechanisms for the soft salt.

Electrochemistry and ECL of a solution containing 1:2 [Ru] $\mathrm{Cl}_{2}$ :TBA[Ir] mixture of the reference complexes were also carried out in the same potential range as [Ir][Ru][Ir] (Figure 1d). While the CVs of $[\mathrm{Ir}][\mathbf{R u}][\mathrm{Ir}]$ and the mixture are similar, there is a large discrepancy in the ECL-voltage curves: the light emission of the mixture follows the same cathodic emission pattern as their reference complexes instead of anodic ECL found in the soft salt. As well, the maximum ECL intensity reached only $56 \mathrm{nA}$ (Figure 1d), with a relative efficiency of $4.37 \%$ compared to $62 \mathrm{nA}$ for [Ir][Ru][Ir] (Figure 1c). The ECL peak wavelength of $635 \mathrm{~nm}$ for the mixture (Figure 1h) matches that of $[\mathbf{I r}][\mathbf{R u}][\mathbf{I r}]$ (Figure 1g).

Extending the potential more positive (Figure 2a), the soft salt undergoes a second irreversible oxidation, to generate $[\mathrm{Ru}]^{3+\cdot}$ (Eq. 5), centred on Ru at $1.48 \mathrm{~V}$, which is very similar to that for the oxidation of $[R u]^{2+}$ in $[R u] C_{2}$ (Figure 1a). The oxidation wave of the Ir moiety was not well resolved due to simultaneous oxidation of the two Ir moieties. However, the two consecutive oxidation current peak heights of the two Ir anions and the Ru cation demonstrate the 2:1 ratio corresponding to the stoichiometry of [Ir][Ru][Ir], see SI Figure S1. More interestingly, upon scanning to further negative potentials (Figure 2a), additional reduction waves were observed. The second and third reduction peaks (Eqs. 6 and 7) possess similar current heights as the first (Eq. 1), which are attributed to further reduction reactions centered on the dtbubpy ligands on $[R u]^{2+}$ by comparison with the literature data. ${ }^{[11]}$

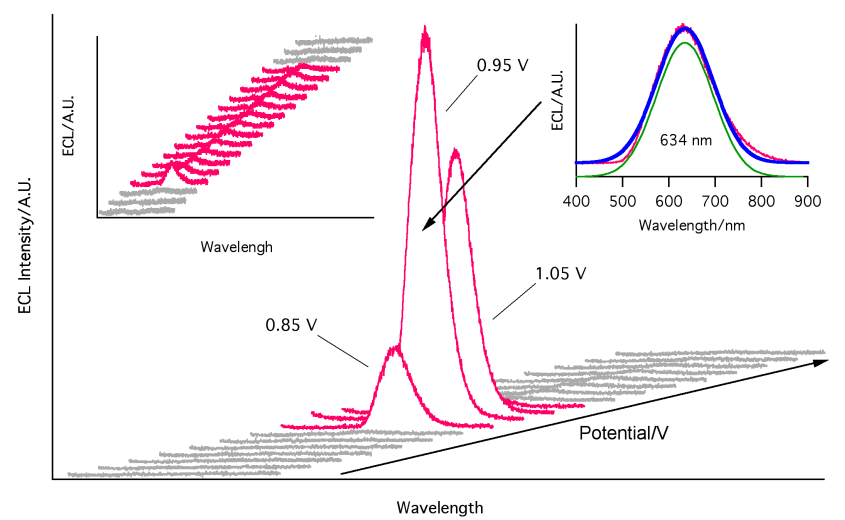

Figure 3. Spooling ECL spectra of [Ir][Ru][Ir] soft salt, first cycle shown, with an extended potential window between $1.43 \mathrm{~V}$ and $2.83 \mathrm{~V}, \mathrm{t}=165 \mathrm{~s}$ for two cycles. Left inset shows the onset $\mathrm{ECL}$ spectra while the right inset illustrates the fitting of ECL spectra to one peak at $634 \mathrm{~nm}$ when the potential was $0.95 \mathrm{~V}$. The applied voltage interval for the ECL spectra is $100 \mathrm{mV}$. 
Scanning to further cathodic potentials reveals two successive reduction reactions of the ppy ligands on both [Ir] anions. When [Ir] was reduced to $[\mathrm{Ir}]^{2}{ }^{-}$(Eq. 8), the electrochemical current was more than 4 times higher than that for the first reduction of the $[\mathrm{Ru}]^{2+}$ moiety. The generated $[\mathrm{Ir}]^{2}$. moiety can reduce $[R u]^{2+}$ in the bulk, to regenerate the $[\mathbf{I r}]$ species (Eq. 9), a catalytic effect. Furthermore, there is almost no such catalytic enhancement on the second reduction of the [Ir] anions (Eq. 10).

$[\mathrm{Ir}]^{*}[\mathrm{Ru}]^{2+}[\mathrm{Ir}] \rightarrow[\mathrm{Ir}]^{\circ}[\mathrm{Ru}]^{3+\cdot}[\mathrm{Ir}]^{\cdot}+\mathrm{e}$

$[\mathrm{Ir}][\mathrm{Ru}]^{+*}[\mathrm{Ir}]+\mathrm{e} \rightarrow[\mathrm{Ir}][\mathrm{Ru}]^{[}[\mathrm{Ir}]$

$[\mathrm{Ir}][\mathrm{Ru}]^{*}[\mathrm{Ir}]+\mathrm{e} \rightarrow[\mathrm{Ir}][\mathrm{Ru}]^{*}[\mathrm{Ir}]$

$[\operatorname{lr}][\mathrm{Ru}]^{\cdot}[\mathrm{Ir}]+2 \mathrm{e} \rightarrow[\mathrm{Ir}]^{2} \cdot[\mathrm{Ru}]^{*}[\mathrm{Ir}]^{2} \cdot$

$$
[\mathrm{Ir}]^{2} \cdot[\mathrm{Ru}]^{\cdot}[\mathrm{Ir}]^{2 \cdot}+2[\mathrm{Ir}][\mathrm{Ru}]^{2+}[\mathrm{Ir}] \rightarrow
$$$$
[\mathrm{Ir}][\mathrm{Ru}]^{*}[\mathrm{Ir}]+2[\mathrm{Ir}][\mathrm{Ru}]^{+\cdot}[\mathrm{Ir}]
$$

$$
[\mathrm{Ir}]^{2} \cdot[\mathrm{Ru}]^{\bullet}[\mathrm{Ir}]^{2 \cdot}+2 \mathrm{e} \rightarrow[\mathrm{Ir}]^{3 \cdot} \cdot[\mathrm{Ru}]^{\bullet}[\mathrm{Ir}]^{3 \cdot}
$$

The ECL-voltage curve in a potential window between 1.48 and $-2.79 \mathrm{~V}$ in Figure 2a demonstrates a dramatic enhancement in ECL intensity in the annihilation path upon generation of $[R u]^{2+*}$. The strong ECL peak reached a maximum intensity of $1118 \mathrm{nA}$. The enhancement in ECL intensity increased

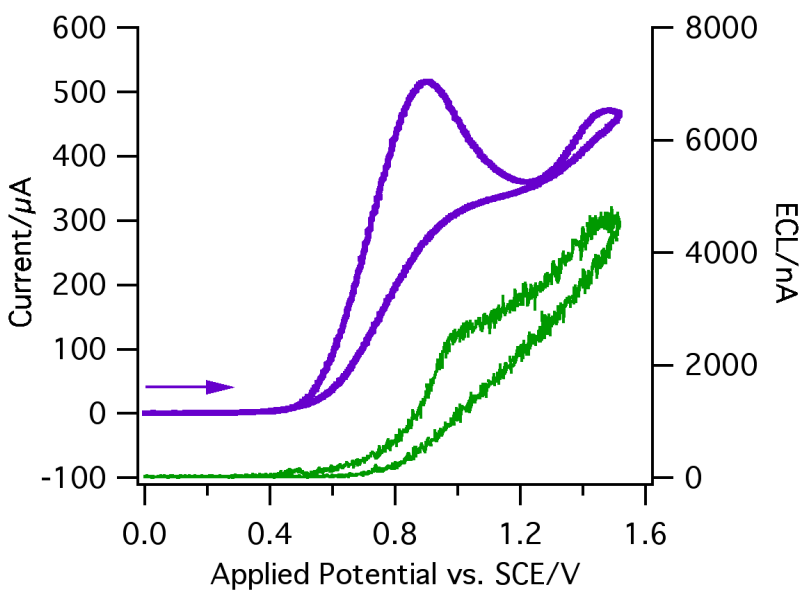

Figure 4. CV (in purple) overlaid with ECL-voltage curve (in green) of [Ir][Ru][Ir] soft salt with $0.02 \mathrm{M}$ TPrA co-reactant, between $0.00 \mathrm{~V}$ to $1.52 \mathrm{~V}$, scan rate was $0.1 \mathrm{~V} / \mathrm{s}$, first cycle shown.

approximately $18 \mathrm{x}$ in Figure 2a compared to Figure 1c. Here, the efficiency increased from $2.51 \%$ to $7.21 \%$, an increase of about $3 x$. It appears that only the $[\mathbf{R u}]^{2+*}$ excited species in this situation can be generated, emitting light via pathways similar to that expressed by Eqs. 3 and 4 .

In comparison, the CV of the $1: 2\left[\mathbf{R u} \mathrm{Cl}_{2}:\right.$ TBA[Ir] mixture solution (Figure $2 b$ ), in this extended potential range displays the sum of those for the two individual complexes, $[\mathbf{R u}] \mathbf{C l}_{2}$ (Figure 1a), and TBA[Ir] (Figure 1b). There is no catalytic current enhancement in the $\mathrm{CV}$, however $\mathrm{ECL}$ was now mostly generated in the anodic potential region compared to Figure 1d, where ECL was only generated in the cathodic region. The potential window must be extended to greater positive potential in order to observe any enhancement with the mixed solution. The maximum ECL, upon oxidation of [Ir], was enhanced much less than with [Ir][Ru][Ir], with an ECL intensity of $414 \mathrm{nA}$. The second ECL peak, as observed in [Ir][Ru][Ir], around $1.28 \mathrm{~V}$ (Figure 2a), does not appear in the 1:2 [Ru] $\mathbf{C l}_{2}$ :TBA[Ir] mixed solution at the same potential. The relative efficiency of the mixed solution was $3.96 \%$, lower than that observed with [Ir][Ru][Ir].

Spooling ECL spectra $\left.{ }^{[9,} 18\right]$ in the extended potential window were recorded for $165 \mathrm{~s}$ at an interval of $1 \mathrm{~s}$ (Figure 3) for one complete cycle (see SI Figure S2 for two complete cycles). Only one peak wavelength at $634 \mathrm{~nm}$ was observed during the ECL evolution and devolution. These spectra clearly exclude the possibility that $[\mathrm{Ir}]^{*}$ excited species was generated, and the second ECL peak in Figure $2 a$ was attributed to the increased concentration of $[\mathrm{Ru}]^{+\cdot}$ moiety caused by the catalytic electrochemical reaction observed in the $\mathrm{CV}$ in Figure 2 (Eq. 9).

The spooling ECL spectra of the $1: 2[\mathbf{R u}] \mathrm{Cl}_{2}:$ TBA[Ir] mixture also show the consistent ECL peak wavelength at 634 $\mathrm{nm}$ from generation of $[R u]^{2+^{*}}$. Furthermore, the $\mathrm{ECL}$ enhancement might be due to the increased concentration of $[R \mathbf{u}]^{+\cdot}$ moiety caused by the catalytic electrochemical reaction, observed in the CV in Figure 2 (Eq. 9), to generate $[R \mathbf{u}]^{2+*}$ (see SI Figure S3). Again, the ECL intensity was weaker than that from [Ir][Ru][Ir]. The soft salt solution containing $20 \mathrm{mM}$ TPrA co-reactant was scanned anodically with a potential window between $0.00 \mathrm{~V}$ and $1.52 \mathrm{~V}$ (Figure 4). TPrA underwent oxidation beginning at $0.48 \mathrm{~V}$, at which the ECL onset was observed. ECL showed a maximum of $140 \mathrm{nA}$ at this potential. In this potential region, neither complex moiety is yet oxidized.

The ECL generation follows the mechanism proposed for $\left[\mathrm{Ru}(\mathrm{bpy})_{3}\right]^{2+} / \mathrm{TPrA}$ co-reactant system in the same situation reported by Miao et al., ${ }^{[2 \mathrm{~b}]}$ involving the TPrA ${ }^{\circ}$ cation radicals as the main driving force (Eq. 12 and 14); i.e. TPrA was oxidized to $\operatorname{TPrA}^{+\cdot}$ (Eq. 11), then rapidly deprotonated to generate the TPrA ${ }^{\circ}$ radical (Eq. 12). The TPrA radical donated an electron to the LUMO of the $[R u]^{2+}$ moiety, generating the $[R u]^{+\cdot}$ species (Eq. 13). At this time, the $\operatorname{TPrA}^{+*}$ radical then removed an electron from the HOMO of $[R u]^{+}$moiety (Eq. 14). Thus, $[R u]^{2+*}$ is generated that will emit light when radiatively relaxing to the ground state (Eq. 4).

$\operatorname{TPrA} \rightarrow \operatorname{TPrA}^{+\cdot}+\mathrm{e}$

$\operatorname{TPrA}^{+\cdot} \rightarrow \operatorname{TPrA}^{\cdot}+\mathrm{H}^{+}$

$[\mathrm{Ir}][\mathrm{Ru}]^{2+}[\mathrm{Ir}]+\mathrm{TPrA} \rightarrow$

$[\mathrm{Ir}][\mathrm{Ru}]^{+*}[\mathrm{Ir}]+\mathrm{Pr}_{2} \mathrm{~N}^{+} \mathrm{C}=\mathrm{HCH}_{2} \mathrm{CH}_{3}$

$[\mathrm{Ir}][\mathrm{Ru}]^{+\cdot}[\mathrm{Ir}]+\operatorname{TPrA}^{+\cdot} \rightarrow[\mathrm{Ir}][\mathrm{Ru}]^{2+*}[\mathrm{Ir}]+\operatorname{TPrA}$

As the potential was scanned more positive, TPrA continued to oxidize and reach a peak at $0.90 \mathrm{~V},{ }^{[19]}$ at which $\mathrm{ECL}$ intensity rose to a maximum of $1430 \mathrm{nA}$. ECL continued to increase from that point while the rising slope decreased. Here, TPrA in the vicinity of the electrode was depleted and therefore 
the $\operatorname{TPrA}^{*}$ concentration decreased. While [Ir] $]^{-}$oxidation to [Ir] ${ }^{\circ}$ in [Ir][Ru][Ir] was initiated and reached a peak at $1.04 \mathrm{~V}, \operatorname{TPrA}$;, with a reduction potential of $-1.70 \mathrm{~V}$ vs. SCE,${ }^{[19]}$ does not have a sufficiently negative potential to reduce $[\mathbf{I r}]-$ to $[\mathbf{I r}]^{2-\bullet}$ with its reduction potential of $-2.33 \mathrm{~V}$ (Figure $2 \mathrm{a}$ ). Again, no [Ir] $]^{*}$ excited state should be generated.

Finally, once the $[R u]^{2+}$ moiety was oxidized around $1.49 \mathrm{~V}$, an enhancement of ECL intensity up to $4800 \mathrm{nA}$ was observed. No reverse oxidation wave was observed, demonstrated by the instability of $\operatorname{TPrA}^{+\cdot}$ due to a fast deprotonation process, as described by Lai and Bard. ${ }^{[19]}$ The addition of TPrA as coreactant to [Ir][Ru][Ir] enhanced the amount of ECL intensity ca. $4 \mathrm{x}$ compared to that under annihilation conditions (from $1118 \mathrm{nA}$, Figure 2a, to 4800 nA, Figure 4).

$[\mathrm{Ir}]^{*}[\mathrm{Ru}]^{3+\cdot}[\mathrm{Ir}]^{\cdot}+\operatorname{TPrA}{ }^{\cdot} \rightarrow[\mathrm{Ir}]^{*}[\mathrm{Ru}]^{2+*}[\mathrm{Ir}]^{\cdot}+\mathrm{Pr}_{2} \mathrm{~N}^{+} \mathrm{C}=\mathrm{HCH}_{2} \mathrm{CH}_{3}$

Here, the $[R u]^{2+}$ species is oxidized to generate $[R u]^{3+\cdot}(E q$ 5). The strong reducing agent, $\operatorname{TPrA}^{\circ}$ (Eq. 12), donates an electron to the LUMO of the $[R \mathbf{R u}]^{3+\cdot}$ species (Eq. 15). This generates the $[R u]^{2+*}$ excited species that emits light. Although the intensity of ECL was $4 x$ higher using TPrA as co-reactant compared to the intensity via annihilation however, the relative ECL efficiency was determined to be $2.67 \%$ compared to $7.21 \%$ from annihilation scanning since the consumption of the electrons went even higher.

Consistent with the above ECL experiments, no [Ir] $]^{*}$ was observed from spooling ECL spectra, Figure 5 . In the same potential range, the spooling spectra showed constant evolution and devolution of peak at $634 \mathrm{~nm}$. This confirms that the [Ru $]^{2+^{*}}$ excited species is the only species that emits light via annihilation or co-reactant studies.

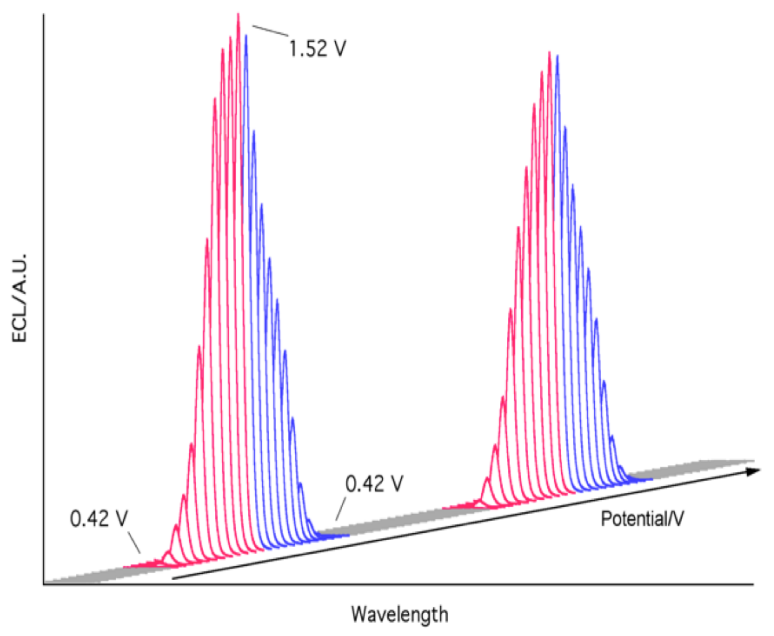

Figure 5. Spooling ECL spectra of $0.1 \mathrm{mM}$ [Ir][Ru][Ir] soft salt with $0.02 \mathrm{M}$ TPrA co-reactant, between $0.00 \mathrm{~V}$ to $1.52 \mathrm{~V}$, with a scan rate of $0.1 \mathrm{~V} / \mathrm{s}$ for two complete cycles, $\mathrm{t}=165 \mathrm{~s}$ (evolution of ECL in pink and devolution of ECL in purple).

\section{Conclusions}

We have demonstrated the contributions from the $[R u]^{2+}$ and [Ir] moieties in $[\mathbf{I r}][\mathbf{R u}][\mathbf{I r}]$ to the ECL generation during electrochemical reactions. It is plausible that the two ions in the [Ir][Ru][Ir] can reduce the energy required to produce ECL in the annihilation path, from 2.56 and $3.30 \mathrm{eV}$ for [Ru ${ }^{2+}$ and [Ir]', respectively, to $2.42 \mathrm{eV}$ for the soft salt (Table 1). Spooling ECL spectroscopy has proven the light emission mechanisms. Here [Ir] ${ }^{-}$acts effectively as a co-reactant, promoting red emission by $[R u]^{2+}$ with remarkable enhanced efficiencies. While the ECL peak wavelength in the annihilation path is consistent at $634 \mathrm{~nm}$ due to the $[R \mathbf{R u}]^{2+\star}$ excited species, ECL intensity is enhanced 18 times in an extended potential window. In the co-reactant route with TPrA, the ECL intensity was a further $4 x$ higher than that in the annihilation path. In both routes, no ECL signal was generated from $[\mathrm{Ir}]^{*}$ moieties due to the electrocatalytic reduction of $[R u]^{2+}$ by $[I r]^{2 \cdot *}$, and insufficient reduction power of TPrA ${ }^{*}$ to generate $[\mathbf{I r}]^{2-*}$.

\section{Experimental}

The electrochemistry and ECL of the soft salt were carried out using a $2 \mathrm{~mm}$ diameter $\mathrm{Pt}$ disc inlaid in a glass sheath as the working electrode (WE), a coiled Pt wire as the counter electrode (CE), and a coiled Pt wire as the quasi-reference electrode (QRE). After each experiment, the electrochemical potential window was calibrated using ferrocence as the internal standard. The redox potential of the ferrocene/ferrocenium $\left(\mathrm{Fc} / \mathrm{Fc}^{+}\right)$couple was taken as $0.40 \mathrm{~V} v s . \mathrm{SCE}^{[20]}$ In annihilation ECL studies, a solution containing approximately $0.1 \mathrm{mM}$ of the molecules, $0.1 \mathrm{M}$ $n \mathrm{Bu}_{4} \mathrm{NPF}_{6}$ as the supporting electrolyte and $3.0 \mathrm{~mL}$ anhydrous acetonitrile was added to the electrochemical cell with a flat Pyrex window at the bottom for detection of generated ECL, which was assembled in a glove box. For co-reactant studies, $20 \mathrm{mM}$ tri- $n$ propylamine was added to the annihilation solution and the airtight cell was assembled in a glove box.

Cyclic voltammetry experiments were performed using a CHI 610A electrochemical analyzer (CH Instruments, Austin, TX). The general experimental parameters for the cyclic voltammetry experiments were as follows: $0.000 \mathrm{~V}$ initial potential in experimental scale, positive or negative initial scan polarity, $0.1 \mathrm{~V}$ $\mathrm{s}^{-1}$ scan rate, 4 sweep segments, $0.001 \mathrm{~V}$ sample interval, $2 \mathrm{~s}$ quiet time, $1.5 \times 10^{-5} \mathrm{AV}^{-1}$ sensitivity. The ECL-voltage curves were obtained using the CHI 610A coupled with a photomultiplier tube (PMT, R928, Hamamatsu, Japan) held at $-750 \mathrm{~V}$ with a high voltage power supply. The ECL was collected by the PMT under the flat Pyrex window at the bottom of the cell, and was measured as a photocurrent before it was transformed to a voltage signal using a picoammeter/voltage source (Keithley 6487, Cleveland, $\mathrm{OH})$. The potential and current signals from the electrochemical workstation and the photocurrent signal from the picoammeter were sent simultaneously through a DAQ board (DAQ 6052E, National Instruments, Austin, TX) to a computer. The data acquisition system was controlled from a custom-made LabVIEW program (ECL_PMT610a.vi, National Instruments, Austin, TX). The photosensitivity on the picoammeter was set manually in order to avoid signal saturation.

ECL spectroscopy was conducted on an Acton 2300i spectrograph with two gratings $(50 \mathrm{l} / \mathrm{mm}$ blazed at $600 \mathrm{~nm}$ and $300 \mathrm{l} / \mathrm{mm}$ blazed at $700 \mathrm{~nm}$ ) and an Andor iDUS CCD camera (Model DU401-BRDD-352). The spectrograph and camera were calibrated using a mercury lamp each time. The ECL spectra were recorded using the Andor Technology program. The accumulated ECL spectra were recorded during two successive potential scan cycles. 


\section{Acknowledgements}

We thank NSERC, CFI, FQRNT, PREA, and The University of Western Ontario for generous financial support to this research. EZ-C thanks the University of St Andrews for support.

Keywords: electrochemiluminescence $\cdot$ iridium $•$ ruthenium • Soft salt $\bullet$ tri- $n$-propylamine

[1] a) A. J. Bard, Electrogenerated Chemiluminescence, Marcel Dekker, New York, 2004; b) W. Miao, Chem. Rev. 2008, 108, 2506-2553; c) M. M. Richter, Chem. Rev. 2004, 104, 3003-3036; d) A. J. Bard, Z. Ding, N. Myung, Struct. Bond 2005, 118, 1-57; e) Z. Ding, B. M. Quinn, S. K. Haram, L. E. Pell, B. A. Korgel, A. J. Bard, Science 2002, 296, 1293-1297; f) L. Hu, G. Xu, Chem. Soc. Rev. 2010, 39, 3275-3304; g) H. C. Moon, T. P. Lodge, C. D. Frisbie, J. Am. Chem. Soc. 2014, 136, 3705-3712; h) M. Sentic, M. Milutinovic, F. Kanoufi, D. Manojlovic, S. Arbault, N. Sojic, Chem. Sci. 2014, 5, 2568-2572; i) E. Kerr, E. H. Doeven, G. J. Barbante, C. F. Hogan, D. J. Bower, P. S. Donnelly, T. U. Connell, P. S. Francis, Chem. Sci. 2015, 6, 472479; j) P. Wu, X. Hou, J.-J. Xu, H.-Y. Chen, Chem. Rev. 2014 114, 11027-11059; k) K. N. Swanick, S. Ladouceur, E. ZysmanColman, Z. Ding, Chem. Commun. 2012, 48, 3179-3181.

[2] a) M.-J. Li, Z. Chen, V. W.-W. Yam, Y. Zu, ACS nano 2008, 2, 905-912; b) W. Miao, J.-P. Choi, A. J. Bard, J. Am. Chem. Soc. 2002, 124, 14478-14485; c) N. E. Tokel, A. J. Bard, J. Am. Chem. Soc. 1972, 94, 2862-2863; d) M.-J. Li, Z. Chen, N. Zhu, V. W.-W. Yam, Y. Zu, Inorg. Chem. 2008, 47, 1218-1223.

[3] a) I.-S. Shin, Y.-T. Kang, J.-K. Lee, H. Kim, T. H. Kim, J. S. Kim, Analyst 2011, 136, 2151-2155; b) E. F. Reid, P. L. Burn, S.-C. Lo, C. F. Hogan, Electrochim. Acta 2013, 100, 72-77; c) S. Zhu, Q. Song, S. Zhang, Y. Ding, J. Mol. Struct. 2013, 1035, 224-230; d) C. Li, J. Lin, Y. Guo, S. Zhang, Chem. Commun. 2011, 47, 4442-4444; e) I.-S. Shin, S. Yoon, J. I. Kim, J.-K. Lee, T. H. Kim, H. Kim, Electrochim. Acta 2011, 56, 6219-6223.

[4] a) R. V. Kiran, C. F. Hogan, B. D. James, D. J. D. Wilson, Eur. J. Inorg. Chem. 2011, 31, 4816-4825; b) S. Zanarini, M. Felici, G. Valenti, M. Marcaccio, L. Prodi, S. Bonacchi, P. ContrerasCarballada, R. M. Williams, M. C. Feiters, R. J. M. Nolte, L. De Cola, F. Paolucci, Chem. Eur. J. 2011, 17, 4640-4647; c) C. Li, J. Lin, X. Yang, J. Wan, J. Organomet. Chem. 2011, 696, 24452450.

[5] a) D. Bruce, M. M. Richter, Anal. Chem. 2002, 74, 1340-1342; b) B. D. Muegge, M. M. Richter, Anal. Chem. 2003, 76, 73-77.

[6] a) E. H. Doeven, E. M. Zammit, G. J. Barbante, C. F. Hogan, N. W. Barnett, P. S. Francis, Angew. Chem. Int. Ed. 2012, 51,
4354-4357; b) E. H. Doeven, E. M. Zammit, G. J. Barbante, P. S Francis, N. W. Barnett, C. F. Hogan, Chem. Sci. 2013, 4, $977-$ 982; c) E. H. Doeven, G. J. Barbante, E. Kerr, C. F. Hogan, J. A. Endler, P. S. Francis, Anal. Chem. 2014, 86, 2727-2732; d) G. J. Barbante, N. Kebede, C. M. Hindson, E. H. Doeven, E. M. Zammit, G. R. Hanson, C. F. Hogan, P. S. Francis, Chemistry 2014, 20, 14026-14031.

[7] a) Q. Shu, L. Birlenbach, M. Schmittel, Inorg. Chem. 2012, 51, 13123-13127; b) M. Schmittel, S. Qinghai, Chem. Commun. 2012, 48, 2707-2709.

[8] M. Schmittel, Q. Shu, M. E. Cinar, Dalton Trans. 2012, 41, 6064-6068.

[9] K. N. Swanick, S. Ladouceur, E. Zysman-Colman, Z. Ding, Angew. Chem. Int. Ed. 2012, 51, 11079-11082.

[10] M. K. Nazeeruddin, R. Humphry-Baker, D. Berner, S. Rivier, L. Zuppiroli, M. Graetzel, J. Am. Chem. Soc. 2003, 125, 87908797.

[11] M. Schwalbe, B. Schäfer, H. Görls, S. Rau, S. Tschierlei, M. Schmitt, J. Popp, G. Vaughan, W. Henry, J. G. Vos, Eur. J. Inorg. Chem. 2008, 21, 3310-3319.

[12] a) M. Mauro, K. C. Schuermann, R. Pretot, A. Hafner, P. Mercandelli, A. Sironi, L. De Cola, Angew. Chem. Int. Ed. 2010, 49, 1222-1226; b) M. Sandroni, E. Zysman-Colman, Dalton Trans. 2014, 43, 3676-3680; c) C. Wu, H.-F. Chen, K.-T. Wong, M. E. Thompson, J. Am. Chem. Soc. 2010, 132, 3133-3139.

[13] K. N. Swanick, J. T. Price, N. D. Jones, Z. Ding, J. Org. Chem. 2012, 77, 5646-5655.

[14] a) S. Bernhard, J. A. Barron, P. L. Houston, H. D. Abruña, J. L. Ruglovsky, X. Gao, G. G. Malliaras, J. Am. Chem. Soc. 2002, 124, 13624; b) D. Di Censo, S. Fantacci, F. De Angelis, C. Klein, N. Evans, K. Kalyanasundaram, H. J. Bolink, M. Gratzel, M. K. Nazeeruddin, Inorg. Chem. 2008, 47, 980-989.

[15] V. V. Pavlishchuk, A. W. Addison, Inorg. Chim. Acta 2000, 298, 97-102.

[16] C. Booker, X. Wang, S. Haroun, J. Zhou, M. Jennings, B. L. Pagenkopf, Z. Ding, Angew. Chem. Int. Ed. 2008, 47, 7731-7735.

[17] A. B. Nepomnyashchii, A. J. Pistner, A. J. Bard, J. Rosenthal, J. Phys. Chem. C 2013, 117, 5599-5609.

[18] a) K. N. Swanick, M. Hesari, M. S. Workentin, Z. Ding, J. Am. Chem. Soc. 2012, 134, 15205-15208; b) M. Hesari, M. S. Workentin, Z. Ding, Chem. Sci. 2014, 5, 3814; c) M. Hesari, M. S. Workentin, Z. Ding, ACS nano 2014, 8, 8543-8553.

[19] R. Y. Lai, A. J. Bard, J. Phys. Chem. A 2003, 107, 3335-3340.

[20] N. G. Connelly, W. E. Geiger, Chemical Reviews 1996, 96, 877-910. 


\section{Full Paper}

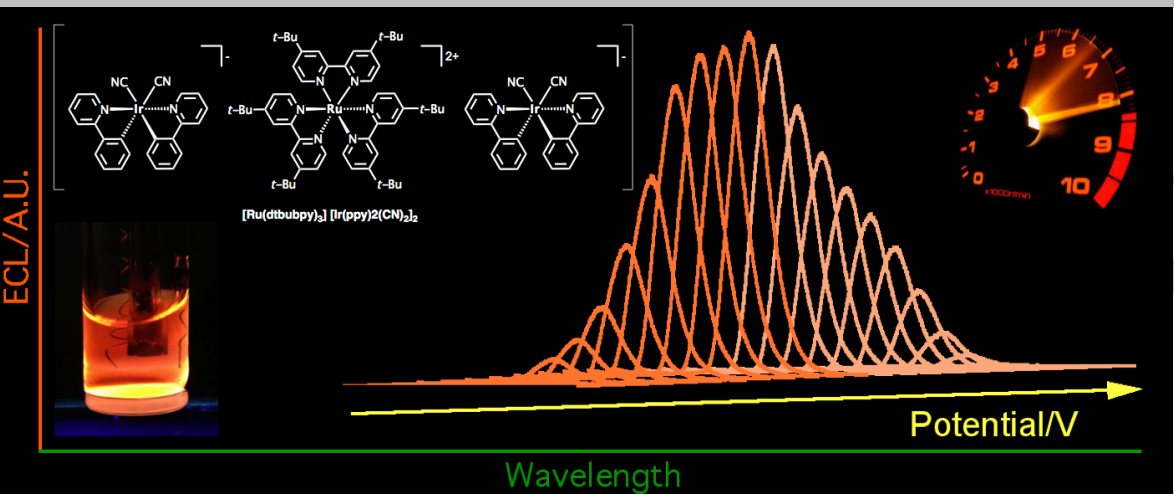

Kalen N. Swanick, Martina Sandroni, Zhifeng Ding, and

Eli Zysman-Colman

*Page No. - Page No.

\section{Enhanced}

Electrochemiluminescence

from a Stoichiometric

Ruthenium(II)-Iridium(III)

Complex Soft Salt

Enhanced electrochemiluminescence (ECL) from a heterometallic soft salt, $\left.[\text { Ru(dtbubpy })_{3}\right]\left[\operatorname{Ir}(\text { ppy })_{2}(\mathrm{CN})_{2}\right]_{2}([\mathbf{I r}][\mathbf{R u}][\mathbf{I r}])$ was discovered to be suitable for the development of efficient and low energy cost ECL detection systems. While ECL intensity in the annihilation path was enhanced $18 \mathrm{x}$, ECL in the co-reactant path with tri- $n$-propylamine was enhanced a further $4 \mathrm{x}$. Spooling ECL spectroscopy unambiguously gives insight into ECL mechanisms: the unique light emission at $634 \mathrm{~nm}$ is due to the [Ru] $]^{2+*}$ and no [Ir] ${ }^{*}$ was generated in either route. 